\title{
Social responsibility organizational focused on disclosure of Forestamp mark differential competitive
}

\author{
Deisy de Castro Costa ${ }^{1}$; Luiz Carlos Magno da Silva Simões ${ }^{1}$; Neirejane do Nascimento Lima ${ }^{1}$ \\ ${ }^{1.2}$ Centro Universitário do Norte (UNINORTE). AV. Joaquim Nabuco, 1469, Centro. Manaus - Amazonas - Brasil. CEP: 69005- \\ 290. Fone: +55 (92) 3215 5000. (deisy.nik@gmail.com, lucapc14@hotmail.com, neyrejanenascimento@ hotmail.com)
}

\begin{abstract}
Social responsibility as a competitive advantage and importance to disclose the company's brand stamping Forestamp, highlighting its concepts and types of strategies used. In this sense, the article aims to strengthen the brand as it reflects the image of the organization as well as disseminating social responsibility and its competitive advantages in the market. The methodology used for this study was exploratory method, based on literature and field research being applied in the case study with a detailed description of the method of data analysis. The results were the implementation of strategic marketing management focused on the disclosure of your brand, emphasizing their social actions, resulting in its strengthening and its value to obtain competitive advantage.
\end{abstract}

Keywords: Organizational Social Responsibility, Marketing, Brand Building, Competitive Edge.

\section{Responsabilidade social organizacional voltado para divulgação da marca Forestamp como diferencial competitivo}

\section{RESUMO}

A responsabilidade social como diferencial competitivo e a importância em divulgar a marca da empresa de estamparia Forestamp, destacando seus conceitos e tipos de estratégias utilizadas. Nesse sentido, o artigo tem como objetivo fortalecer a marca uma vez que ela reflete a imagem da organização, assim como disseminar a responsabilidade social e suas vantagens competitivas no mercado. A metodologia utilizada para este estudo foi o método exploratório, com base em pesquisas bibliográficas e de campo sendo aplicado no estudo de caso com uma descrição detalhada do método de análise de dados. Os resultados encontrados foram à implementação de gestão estratégica de marketing voltada para a divulgação de sua marca, enfatizando suas ações sociais, resultando em seu fortalecimento e sua obtenção de valor como diferencial competitivo.

Palavras Chaves: Responsabilidade Social Organizacional, Marketing, Fortalecimento da marca, Diferencial Competitivo.

\section{INTRODUÇÃO}

A escolha da temática responsabilidade social organizacional voltado para divulgação da marca Forestamp como diferencial competitivo se deu em razão dos resultados obtidos através dos instrumentos de pesquisa e análise crítica do gráfico radar dos $10 \mathrm{M}$ 's, onde a área que apresentou um dos pontos fracos foi o setor de Marketing. Marketing é uma área do conhecimento que engloba atividades direcionadas as relações de trocas, orientadas para a satisfação dos desejos e necessidades dos clientes, visando alcançar determinados objetivos de empresas ou indivíduos e considerando sempre o meio ambiente de atuação e o impacto destas relações com a sociedade [1].

A empresa não tem a sua marca muito conhecida e lembrada. Por esta razão, observou-se a necessidade de implantar melhorias nos procedimentos de divulgação do nome da organização, com o objetivo de fortalecer a marca uma vez que ela reflete a imagem da organização, assim como disseminar a responsabilidade social e suas vantagens competitivas no mercado para seu publico alvo e em potencial. Com o desenvolvimento e a modernização da área detectada para aperfeiçoar a sua imagem, justifica a relevância de se manter no mercado de estamparia e confecção como uma empresa de excelência. Sendo assim, a contribuição do programa de marketing para causas sociais pode ser desenvolvida por meio de uma aliança estratégica entre uma empresa e uma organização voluntaria ou beneficente comprometida com a área de interesse sócias definida ou diretamente em beneficio da causa em si [2].

Com a resolução do problema diagnosticado, a organização ira atingir a mente do consumidor através de propagandas e divulgação, tendo como beneficio um retorno em curto prazo e a preferência pela marca do seu publico alvo. A preocupação com os efeitos sociais e ambientais das atividades de

ITEGAM - JETIA Vol. 02, Nº 07. Mês de ano. Manaus - Amazonas, Brasil. ISSN 2447-0228 (ONLINE). 
Deisy de C. Costa, Luiz C. M. da S. Simões, Neirejane do N. Lima / ITEGAM-JETIA Vol.02, N07, pp.62-68. Setembro, 2016

empresas, bem como com os valores éticos e morais, suscita muitas discussões no meio empresarial [3].

\section{REVISÃO BIBLIOGRÁFICA}

\section{II.1 RESPONSABILIDADES SOCIAIS - VANTAGENS E DESVANTAGENS PARA AS EMPRESAS.}

A Responsabilidade Social não se restringe apenas à organização, mas envolve toda a sua área de influência e seus funcionários, caracterizando-se como um modo de a empresa ser competitiva, conquistar e ampliar o mercado. Isso porque a Responsabilidade Social não pode ser destacada como uma ação caridosa ou como uma beneficência isolada, motivada por um sentimento de culpa decorrido da utilização dos recursos da sociedade, ou por iniciativa unilateral do empresário, mas, sim, alinhada aos objetivos da empresa, que devem contemplar a responsabilidade social [4].

A vantagem do marketing verde é um importante diferencial para as organizações e obtenção de vantagem comparativa, otimizando a estratégia de divulgação da marca da empresa melhorando sua imagem e garantindo a satisfação de seus clientes com seus produtos e serviços.

Algumas benfeitorias da Responsabilidade Social voltada para as empresas podem ser comentados em vantagens como: o fortalecimento da marca e imagem da organização; a caracterização perante aos concorrentes; a geração de mídia espontânea; a fidelização de clientes; a segurança patrimonial e dos funcionários; a atração e retenção de talentos profissionais; a proteção contra ação negativa de funcionários; a menor ocorrência de controles e auditorias de órgãos externos; a atração de investidores e deduções fiscais [5].

Conforme apresenta a tabela 1 .

Tabela 1- Pontos fortes, fracos e a melhorar da área de Meio Ambiente.

\begin{tabular}{|c|c|c|c|c|c|}
\hline & Seq & Atributos & $\begin{array}{l}\text { Ponto } \\
\text { Forte }\end{array}$ & $\begin{array}{l}\text { Ponto a } \\
\text { melhorar }\end{array}$ & $\begin{array}{l}\text { Ponto } \\
\text { Fraco }\end{array}$ \\
\hline \multirow{6}{*}{ 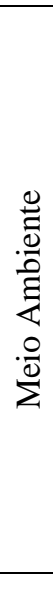 } & 1 & $\begin{array}{ll}\text { Gestão } & \text { de } \\
\text { proteção } & \text { de } \\
\text { ambiental } & \end{array}$ & & 5 & 1 \\
\hline & 2 & $\begin{array}{l}\text { Programas de } \\
\text { economia de } \\
\text { energia elétrica }\end{array}$ & 3 & 3 & \\
\hline & 3 & $\begin{array}{ll}\text { Programas } & \text { de } \\
\text { economia } & \text { de } \\
\text { água } & \end{array}$ & 3 & 3 & \\
\hline & 4 & $\begin{array}{ll}\text { Programas } & \text { de } \\
\text { economia } & \text { de } \\
\text { insumos } & \\
\end{array}$ & 3 & 3 & \\
\hline & 5 & $\begin{array}{l}\text { Coleta de lixo } \\
\text { seletiva }\end{array}$ & 2 & 4 & \\
\hline & & TOTAL & 11 & 18 & 1 \\
\hline
\end{tabular}

Observou-se que seus gestores têm ciência em relação às questões ambientais, portanto a empresa demonstrou ter dado os primeiros passos trabalhando de maneira harmoniosa para que houvesse a conscientização entre seus funcionários, por outro lado, sabe-se que a legislação não obriga a adoção de nenhuma normatização ambiental, ou seja, essa conscientização foi realizada pelos próprios gestores não apenas em questões ambientais bem como na redução de energia elétrica e no consumo excessivo de água e insumos.

\section{II.2 RESPONSABILIDADE SOCIAL COMO FATOR COMPETITIVO}

A responsabilidade social, adquirida de forma sólida e inteligente pela empresa, pode contribuir de forma decisiva para a sustentabilidade e o desempenho empresarial. Cada vez mais, valoriza-se a acordar de que uma gestão socialmente responsável pode trazer numerosos benefícios às empresas.

Em muitos depoimentos e pesquisas, a responsabilidade social aparece como responsável pelo apoio da sociedade e dos consumidores, pela preferência de investidores internacionais, por um espaço crescente aberto pela mídia, por um bom clima organizacional, pelo recrutamento e retenção de pessoas talentosas. Esses resultados com a responsabilidade social procederiam no chamado retorno social institucional.

O retorno social institucional ocorre quando a maioria dos consumidores privilegia a atitude da empresa de investir em ações sociais, e o desempenho da empresa obtém o reconhecimento público [5]. Como consequência, a empresa vira notícia, potencializa sua marca, reforça sua imagem, assegura à lealdade de seus empregados, fideliza clientes, reforça laços com parceiros, conquista novos clientes, aumenta sua participação no mercado, conquista novos mercados e desenvolve suas vendas.

No entanto, as empresas que adotam a responsabilidade social podem alcançar muitas vantagens nos mais variados sentidos, desde a influência positiva na imagem da empresa diante do mercado até a criação de uma sociedade mais justa que, em última veemência, será imprescindível para a continuidade da empresa.

\section{II.3 A MARCA COMO DIFERENCIAL COMPETITIVO}

A empresa tem além de seus produtos e serviços à marca como um de seus principais diferenciais competitivos, nela esta expressa toda sua tradição, ética, valores, princípios e diferenciais que acabam influenciando positivamente no Marketing da organização tornando a marca da empresa confiável perante seu público e todos os interessados pela organização. A marca saiu do âmbito da engenharia de produto para o aspecto da cultura de consumo, formada pela percepção dos consumidores a partir de experiências com o produto e com a organização [6].

O diferencial competitivo de uma organização tem que ser único precisa ser desejado e buscado para agregar valor para os clientes e que satisfaça as suas necessidades garantindo assim a empresa uma vantagem competitiva frente a seus concorrentes, pois essa vantagem faz com que a oferta da empresa seja escolhida pelos seus clientes, e clientes em potenciais, dentre todas as ofertas disponíveis no seu mercado de atuação. 


\section{II.4 A IMPORTÂNCIA DA DIVULGAÇÃO DA MARCA}

Quanto mais conhecida for à marca da empresa maior será sua chance de vender um produto ou um serviço, pois uma marca forte e bem divulgada tem como objetivo construir uma imagem favorável na mente dos consumidores, tendo assim maior influencia sobre os clientes atuais e potenciais da organização, pois a imagem sempre está em oposição à realidade, uma vez que a imagem é criada, construída para um determinado fim. Desta maneira as pessoas percebem, conhecem e acreditam na imagem organizacional [7].

A marca fortemente divulgada faz com que o público tenha uma imagem favorável da organização para isso e preciso usar a comunicação adequada para seu público-alvo, e a propaganda é a forma que as empresas encontram para promover o produto, potencializar as vendas e conquistar novos mercados, pois a propaganda é a comunicação de caráter variado (político, religioso, econômico, social, etc...) voltada ao convencimento daquele que toma conhecimento de sua mensagem [8].

\section{II.5 DIVULGAÇÃO DA MARCA NA INTERNET}

A internet é atualmente uma das principais formas de divulgação de marcas, devido à grande procura por consumidores por essa ferramenta de comunicação, pois com o aumento do poder de compra da população e uma maior acessibilidade à telefonia móvel, a internet permite que uma organização atinja a maior quantidade de pessoas que tenham interesse por um produto ou serviço.

Empresas que investem na divulgação da marca na internet se beneficiaram da ótima relação de custo beneficio que há em investir e anunciar nesse meio de comunicação, pois a marca que tem uma excelente divulgação para seu público, dificilmente será esquecida, pois estará sempre se reinventando e surpreendendo seus consumidores. Logo, a Internet, como meio de divulgação e promoção de marcas, fará com que a relação das pessoas com as marcas sejam uma conjunção de experiências, trocas, percepções tentativas e erro, pensamento e experiências, tudo simultaneamente, no mesmo lugar [9].

São diversas as maneiras de divulgação na internet como: sites, blogs, links patrocinados, e-mail e as redes sociais que podem ser uma valiosa oportunidade de fidelizar os clientes, pois as redes sociais permitem as empresas uma rápida comunicação com os consumidores atuais e futuros ajudando ainda na conquista de novos mercados. Principalmente devido ao fato dos rastros desses grupos tornarem-se visíveis na Rede, o interesse na perspectiva de analise mostrou-se renovado nos últimos anos [10].

\section{II.6 A ESTRATÉGIA DE CUSTO BENEFÍCIO DA DIVULGAÇÃO}

Toda empresa fixa seus esforços na maximização de seus lucros e na otimização de seus processos produtivos, porém nos últimos anos o investimento na divulgação da marca vem ganhando espaço nas organizações.
Para isso as empresas estão criando estratégias para que o custo benefício através da divulgação da marca por meio de propagandas possa torná-las mais conhecidas pelo seu publico e melhorar o relacionamento com a clientela desejada agregando valor a marcar.

A propaganda [...] tem o poder de melhorar a quantidade percebida da marca e, por conseguinte, a habilidade dos gerentes da marca em cobrar preços mais altos: ou seja, os consumidores estão dispostos a pagar mais por marcas que eles percebem como tendo melhor qualidade considerando todos os elementos, os argumentos a favor de investir em propaganda são baseados na crença de que ela pode aumentar a lucratividade aumentando o volume de vendas, permitindo preços de vendas mais altos, e assim, aumentando o faturamento além da despesa de propaganda incrementada [11].

A ferramenta mais viável para essa divulgação é a internet, pois com um investimento menor proporcionar uma maior margem de lucro agregando valor à marca e satisfazendo os clientes da organização através de uma eficiente divulgação dos produtos e serviços. Divulgar a empresa com menor custo benefício pode se tornar um importante diferencial competitivo para as organizações ganhando maior visibilidade chegando a atingir outros mercados, a venda através da rede proporciona às empresas uma visibilidade, não só em todo o território brasileiro, mas também em qualquer parte do mundo [12].

De acordo com a tabela 2, o conhecimento do mercado e dos concorrentes, houve uma incidência de empate como ponto forte e a melhorar. Notou-se claramente que a empresa consegue identificar seu ramo de atuação no mercado assim como seus concorrentes, facilitando seu planejamento estratégico competitivo para se manter no mercado.

\begin{tabular}{|c|c|c|c|c|c|}
\hline & Seq & Atributos & $\begin{array}{l}\text { Ponto } \\
\text { Forte }\end{array}$ & $\begin{array}{l}\text { Ponto a } \\
\text { melhorar }\end{array}$ & $\begin{array}{l}\text { Ponto } \\
\text { Fraco }\end{array}$ \\
\hline \multirow{6}{*}{ 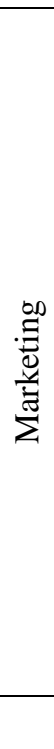 } & 1 & $\begin{array}{l}\text { Conheciment } \\
\text { o do mercado } \\
\text { er dos } \\
\text { concorrentes }\end{array}$ & 3 & 3 & \\
\hline & 2 & $\begin{array}{l}\text { Flexibilidade } \\
\text { e } \\
\text { negociações }\end{array}$ & 6 & & \\
\hline & 3 & $\begin{array}{l}\text { Lançamento } \\
\text { de produtos e } \\
\text { campanhas }\end{array}$ & 1 & 2 & 3 \\
\hline & 4 & $\begin{array}{l}\text { Pós-venda, } \\
\text { garantia } \\
\text { assistência } \\
\text { técnica }\end{array}$ & 4 & 2 & \\
\hline & 5 & $\begin{array}{l}\text { Tratamento } \\
\text { de satisfação } \\
\text { dos clientes }\end{array}$ & 5 & 1 & \\
\hline & & TOTAL & 19 & 8 & 3 \\
\hline
\end{tabular}

Fonte: Os autores, (2015). 
Deisy de C. Costa, Luiz C. M. da S. Simões, Neirejane do N. Lima / ITEGAM-JETIA Vol.02, Nº7, pp.62-68. Setembro, 2016

\section{MATERIAIS E MÉTODOS}

A metodologia utilizada para esse estudo foi o estudo de caso, com o método exploratório, de invento qualitativo, pois o objetivo é mostrar que as estratégias de persuasão e de disseminação são criadas para fortalecer a marca [13]. Para a constituição do tema abordado foi realizada uma pesquisa, com a finalidade de originar informações que irão mostrar a importância de se descobrir o problema pesquisado e as soluções para a divulgação da marca com a responsabilidade social da empresa.

O método exploratório facilitou o conhecimento e uma melhor compreensão do tema abordado e proporcionou maior compreensão dos fatos e conceitos relacionados com os fenômenos estudados. A pesquisa qualitativa mostra dependendo de seu contexto descrições interpretativas ou naturalistas, informações flexíveis adequadas às estruturas teóricas do objeto em pesquisa.

Com base em pesquisas bibliográficas e de campo as informações coletadas na empresa deram-se através de dados primários e secundários como: entrevista, livros e pela internet. Varias fontes foram utilizadas para este trabalho, através dos dados coletados e dos materiais estudados. A pesquisa bibliográfica é aquela elaborada a partir de material já publicado, constituído principalmente de livros e artigos periódicos.

Dentre os meios de comunicação verificou-se que alguns não seriam viáveis para a organização como: o radio, a televisão, esses meios de comunicação não atingem o publico em geral, com isso verificou-se que um meio eficaz de disseminação da marca com responsabilidade social seria a internet, por ser nos dias atuais uma das principais fontes de divulgação. São diversas as maneiras de divulgar a marca Forestamp na internet como: sites, blogs, links patrocinados, e-mail e as redes sociais que podem ser uma valiosa oportunidade de fidelizar os clientes, pois as redes sociais permitem uma rápida comunicação com os consumidores atuais e futuros.

\section{APRESENTAÇÃO DO ESTUDO DE CASO}

Num mundo globalizado e com constantes mudanças repentinas e muitas vezes drásticas, as organizações através de seus gestores, necessitam desenvolver habilidades que os permitam visualizar de uma forma holística, compreendendo toda a conjuntura que envolve a organização, seja em aspectos internos ou externos, minimizando possíveis vulnerabilidades que a organização possua.

Define-se microempresa como $[\ldots]$ empresas de dimensões reduzidas que, dada a sua precariedade tecnológica, possuem uma composição orgânica que favorece sua "parte variável" (e seus fatores subjetivos), por cima da "composição média" de um ramo determinado, em detrimento de sua "parte constante" [14].

De acordo com o Serviço Brasileiro de Apoio às Micros e Pequenas Empresas [15] a classificação quanto ao porte, segmento e número de funcionários dos micros, pequenas, médias e grandes empresas, é dada desta forma, conforme apresenta a tabela 3.

Tabela 3 - Classificação Quanto ao Porte, Segmento e número de Funcionários.

\begin{tabular}{c|c|c|c|l}
\hline PORTE & SERVIÇOS & COMÉRCIO & INDÚSTRIA & \\
\hline Micro & Até 09 & Até 09 & Até 19 & Funcionários \\
\hline Pequena & De 10 a 49 & De 10 a 49 & De 20 a 99 & Funcionários \\
\hline Média & De 50 a 99 & De 50 a 99 & De 100 a 499 & Funcionários \\
\hline Grande & Mais de 100 & Mais de 100 & Mais de 500 & Funcionários \\
\hline
\end{tabular}

Fonte: [15].

Com base no exposto acima, e utilizando a técnica de observação direta, através de entrevistas e questionários com gestores e colaboradores, e ainda análise documental da empresa, constatou-se que a empresa Forestamp é considerada uma microempresa (ME), pois esta é uma indústria de confecções.

Os profissionais atuantes foram recrutados baseados em sua qualificação, competência e capacidade e colaboram para o bom desempenho das atividades da organização. Os mesmos se encontram na faixa etária que varia entre 20 e 59 anos, logo podese notar que as faixas etárias de que demonstram pequena predominância na empresa, são dos colaboradores que se encontram nas faixas etárias de 30 a 49 anos, porém com mínima tendência à classe de 40 a 49 anos. Conforme mostra a figura 1:

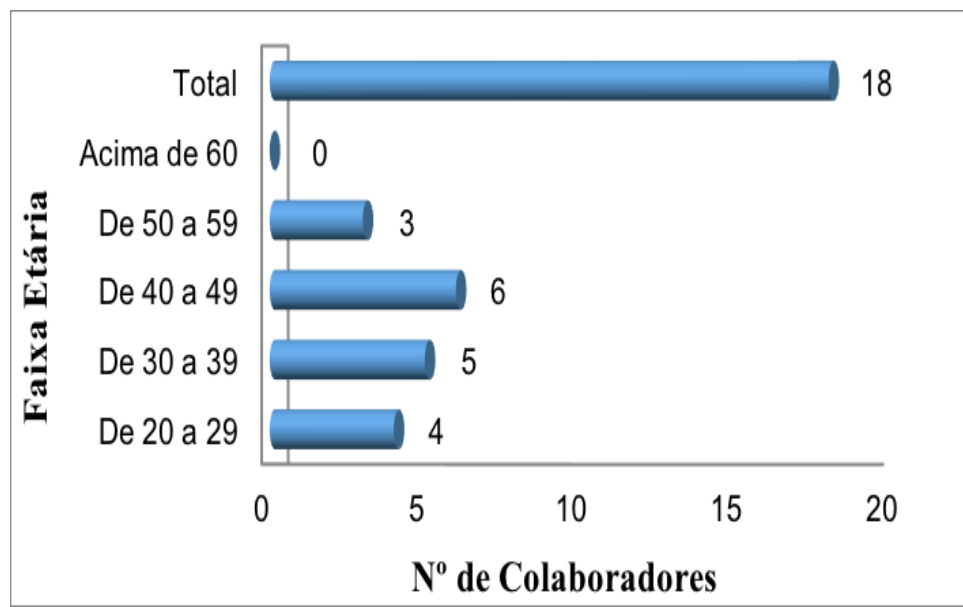

Figura 1 - Número de colaboradores por faixa etária.

Fonte: Os autores, (2015).

\section{IV.1 GRÁFICO RADAR}

Nesta seção, considera-se o uso de gráfico tipo radar, um tipo de gráfico permite representar séries temporais cíclicas e comparar os valores da série com o valor de sua média aritmética [16]. Trata-se de um gráfico construído de forma circular, espalhando-se, de forma radial, as dez áreas mencionadas. Trata-se de um gráfico construído de forma circular, espalhando-se de forma radial, as dez áreas mencionadas, onde estas representam as 
áreas cruciais da organização que merecem a concentração e foco, por se tratarem de pontos estratégicos.

A aplicação do gráfico radar na empresa induz toda a equipe à autoanálise, ao responder o questionário e possibilidade de visualização desta "impressão digital" ou radiografia institucional em forma de um polígono, onde cada área interna avaliada tem sua posição definida em uma das cinco zonas do gráfico, baseado na tabulação dos dados obtidos no questionário de auto avaliação institucional, que indicam o quantitativo de respostas referentes aos pontos fortes, a melhorar e fracos, assim forma-se alicerce para disposição das dez grandes áreas (10-Ms) em cinco zonas, que estas se classificam em cinco categorias e são respectivamente, representadas do centro para as suas extremidades pelas seguintes cores, $1^{\circ}$ azul, $2^{\circ}$ verde, $3^{\circ}$ amarelo, $4^{\circ}$ vermelho e $5^{\circ}$ roxo [17].

O gráfico da figura 2 evidencia claramente a distribuição dos 10-Ms do autodiagnóstico da empresa Forestamp, no que se refere às áreas criticas, conforme são classificados quanto mais próximo do centro estiver o atributo, melhor estará a empresa naquele aspecto; quanto mais distante do centro, pior [17].

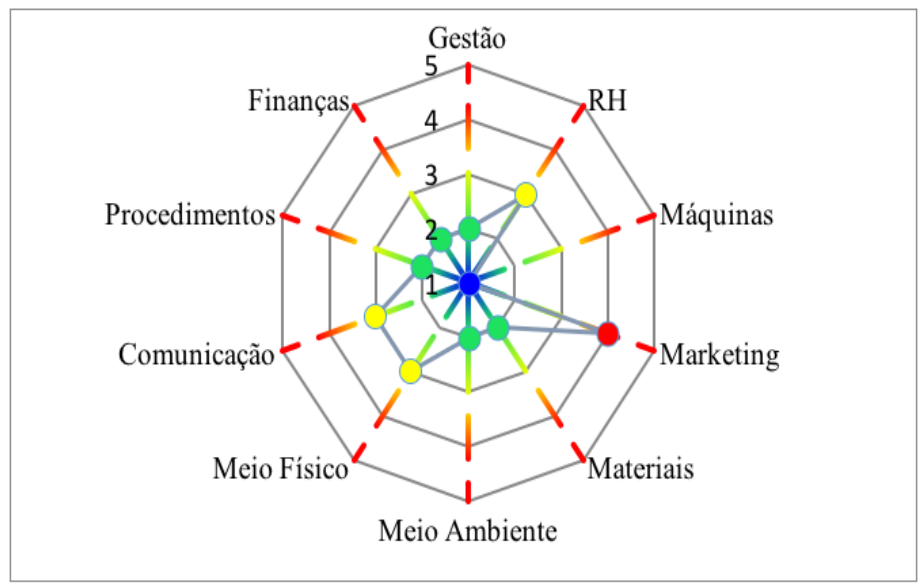

Figura 2 - Gráfico das áreas críticas.

Fonte: Os autores, (2015).

\section{IV.2 ORGANOGRAMA ORGANIZACIONAL}

O organograma é um instrumento de trabalho utilizado pelo administrador para representar de forma gráfica a estrutura organizacional de uma empresa. Ele permite a interpretação das relações de autoridades hierárquicas de forma rápida e eficaz, demonstrando os vários conceitos aplicados no desenho [18].

Os dados que foram coletados na entrevista, e através da pesquisa documental observou-se que a empresa não possui organograma. Sendo assim, este é um ponto fraco para a empresa, pois quando a empresa está em fase de desenvolvimento ela precisa criar o seu organograma para que os seus funcionários fiquem informados quais os níveis hierárquicos que existem na organização e qual a relação da autoridade de cada um, e quem é responsável por cada setor, o organograma deve mostrar claramente a espinha dorsal de sua empresa e permitir um crescimento futuro [19].
Entretanto, com base nas informações e dados fornecidos pela organização, é apresentado abaixo o demonstrativo de como foi sugerido o quadro funcional da organização, chamado de organograma funcional na figura 3 .

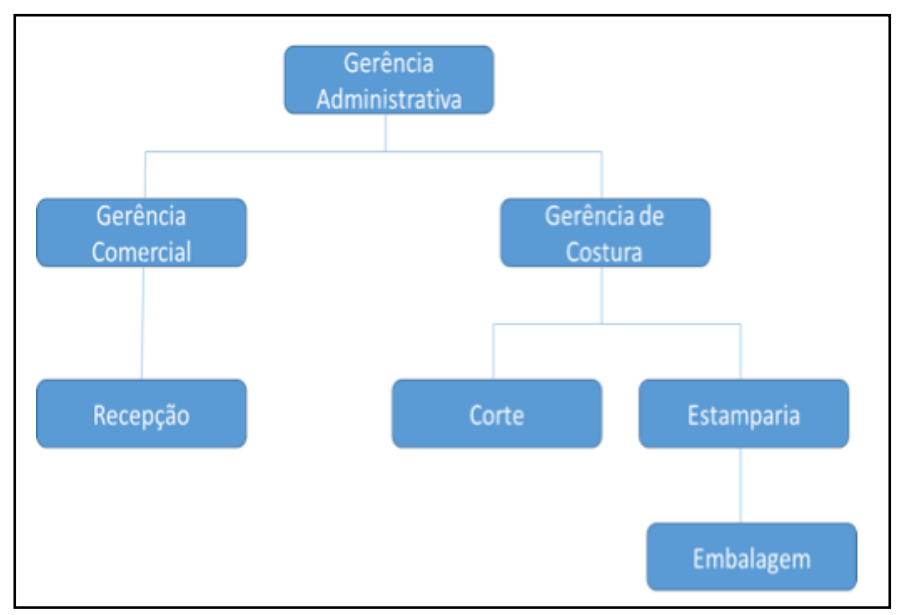

Figura 3 - Organograma da Empresa Forestamp. Fonte: Os autores, (2015).

$\mathrm{Na}$ empresa observou-se que o maior quantitativo de funcionários está concentrado no nível operacional, pois a distribuição das funções para o desempenho das atividades atende de forma satisfatória as necessidades da empresa, uma vez que há entre os colaboradores uma rotatividade de tarefas servindo como troca de experiências e conhecimento entre os diversos processos nesse ramo. Segundo [20] "A rotação de cargos envolve a movimentação de uma pessoa de um cargo para outro a fim de obter melhor compreensão da organização como um todo". Conforme mostra a figura 4

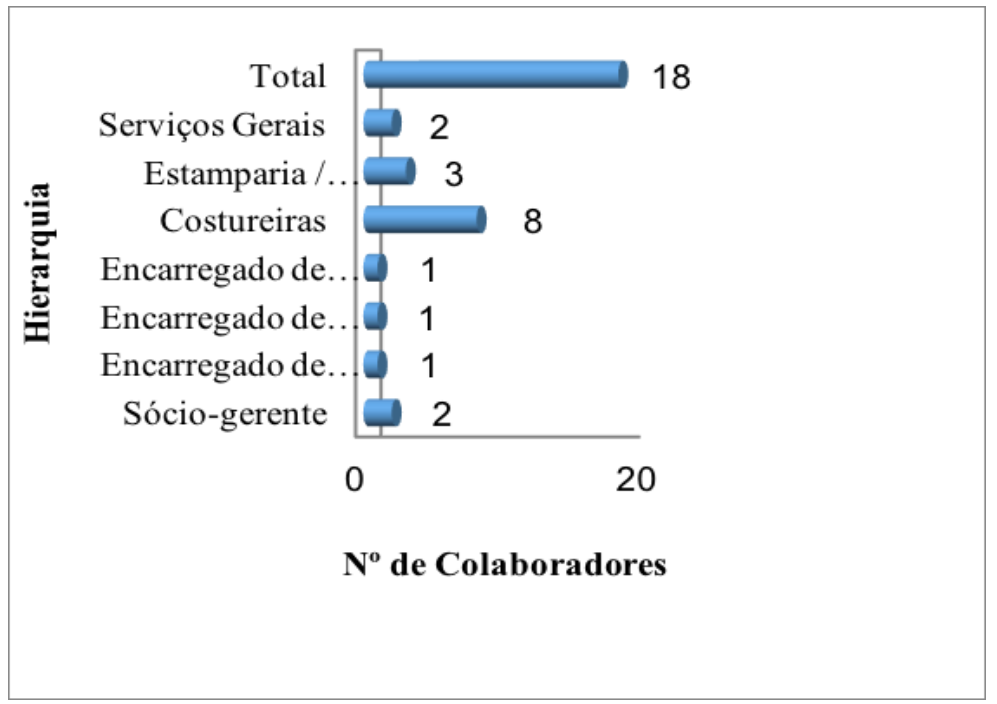

Figura 4 - Número de colaboradores por hierarquia. Fonte: Os autores, (2015). 


\section{IV.3 VANTAGEM COMPETITIVA}

A tecnologia abrange o conjunto de conhecimento aplicado para a obtenção de determinado fim [21]. De acordo com a pesquisa por meio de entrevista, questionário e observação direta com gestores e colaboradores, constatou-se que as tecnologias utilizadas pela empresa são: computadores, ar-condicionado, internet, maquina de sublimação para a impressão do papel de transfer da arte, maquina de prensa para pressionar o papel e aquecer até 200 graus, e o calor e a pressão farão que a tinta seja transferida para o produto e máquina de costura.

Esses diferenciais competitivos são importantes para que a empresa tenha uma vantagem estratégica no mercado em que atua. Pois a vantagem competitiva de uma empresa, ou seja, o valor que se cria para o consumidor [...] advém do fato de a empresa operar com baixo custo ou com diferenciação [22].

A empresa como um todo conhece seu diferencial e busca soluções inovadoras para atender as necessidades de seus clientes, pois mantendo seus diferenciais competitivos, continuará solucionando as mais variadas necessidades de seus clientes e se destacando no mercado em que atua a vantagem competitiva surge essencialmente do valor que uma empresa consegue criar para seus compradores.

\section{IV.4 ANÁLISES, RESULTADOS E DISCUSSÕES}

Atualmente, uma das condições para a empresa obter lucro e ser competitiva é relacionar sua marca a conceitos e valores éticos. Com isso as organizações buscam na Responsabilidade Social benefícios como o reforço de seus projetos sociais por ela financiados, assim a organização pode torna-se mais conhecida e vender mais.

A marca, os seus produtos e serviços podem ganhar maior visibilidade. Os clientes podem orgulhar-se de comprar produtos ou contratar serviços de uma empresa com elevada Responsabilidade Social. A não adoção da empresa por uma política de estratégia de divulgação de sua marca ocasionará um não reconhecimento da mesma fazendo que a organização perca espaço no mercado para seus concorrentes e sua marca poderá ficar esquecida pelo seu público alvo.

A utilização da responsabilidade social para a disseminação da marca trará um diferencial competitivo para a divulgação da marca fazendo com que a organização ganhe mais espaço no mercado em que atua tornando-se mais reconhecida pelos seus clientes atuais e em potencial, reduzindo os custos, pois agregará valor a marca e irá melhorar a sua imagem, já que o marketing verde como e conhecido a responsabilidade social gera um valor incomensurável perante a sociedade.

\section{CONCLUSÕES}

Para a organização não basta, no entanto, criar marcas para impactar temporadas, é essencial que se mantenha em andamento para que se perpetue. A empresa Forestamp fortaleceu a sua imagem, ganhou respeito, confiabilidade e assegurou a sua autopreservação com o uso da cidadania empresarial como vantagem competitiva. Dessa maneira, com a implementação da gestão estratégica de Marketing voltada para a divulgação de sua marca, a empresa alcançou o seu objetivo de fortalecer a sua marca, ressaltando suas ações sociais e ficou reconhecida no mercado pelo seu diferencial competitivo, potencializando a sua imagem.

Portanto, a importância de se estudar um meio de divulgação da marca com responsabilidade social, pode ser explicada pela necessidade de dissemina-la para mostrar o seu diferencial competitivo e suas estratégias. A organização deve confiar que a melhor estratégia de marketing é o fato perfeito ou a qualidade do serviço é o mais importante e primordial para vantagem competitiva no mercado. Pois é mais viável criar estratégias que concordem com os recursos e aspectos exclusivos da organização que não poderão ser copiados pelos concorrentes.

\section{AGRADECIMENTOS}

Ao Centro Universitário do Norte (UNINORTE) e a empresa Forestamp, pelo apoio a realização desta pesquisa.

\section{REFERÊNCIAS}

[1]. LAS CASAS, Alexandre Luzzi. Marketing: conceitos, exercícios e casos. 3. Ed. São Paulo: Atlas, 2002.

[2]. THOMPSON, Marjorie; PRINGLE, Hamish. Marketing social: marketing para causas sociais e a construção das marcas. São Paulo: Makron Books, p. 03, 2000.

[3]. LEVEK, Andrea Regina H. Cunha; BENAZZI, Ana Cristina Moraes; ARNONE, Janaína Ribeiro Falcão; SEGUIN, Janaína; GERHARDT, Tatiana Monteiro; A responsabilidade social e sua interface com o marketing social. Curitiba, p. 6, 2002.

[4]. ORCHIS, Marcelo A. et al. Responsabilidade Social das empresas: a contribuição das universidades. São Paulo: Petrópolis, p. 4, 2002.

[5]. MELO NETO, Francisco Paulo de; FRÓES, Cesar. Responsabilidade social \& cidadania empresarial: administração do terceiro setor. Rio de Janeiro: Qualitymark, p. $5,1999$.

[6]. CAPUTO, Érica Saião; NOGUEIRA, Heloisa Guimarães Peixoto; MACEDO, Marcelo Álvaro da Silva. Avaliação de Marcas: uma Aplicação ao Caso Bombril, Rio de Janeiro, dezembro, 2008. Disponível em: <http://www.raeeletronica/index.cfm?FuseAction $=$ Artigos $\& I D=5364 \&$ Secao $=A R$ TIGOS\&Volume $=7 \&$ Numero=2\&Ano2008 $>$. Acesso em: 31 de março de 2014

[7]. CARISSIMI, João. Reflexões sobre os processos organizacionais utilizados pelas relações públicas na construção da imagem organizacional, Campo Grande, setembro, p. $\quad 09, \quad 2011 . \quad$ Disponível em:<www.intercom.org.br/papers/nacionais/2001/papers/NP5CA RISSIMI.PDF>. Acesso em: 31 de março de 2014. 
[8]. CABRAL, André Luiz Cavalcanti. Aspectos Jurídicos da Publicidade, João Pessoa, junho, p. 04, 2003. Disponível em: <http://www.ccj.ufpg.br/primafacie>. Acesso em: 31 de março de 2014.

[9]. PERROTA, Karem; TOLEDO, Luciano. O posicionamento da marca sob a ótica da internet. São Paulo, p. 11, 2006. Disponível em: <periódicos. unifacef.com.br/index.php/article/view/File/199/51>. Acesso em: 31 de marçode 2014.

[10]. RECUERO, Raquel. Redes Sociais na Internet, Difusão de Informações e Jornalismo: Elementos para discussão. P. 02, 2012. Disponível em: <www.raquelrecuero.com/artigoredesjornalismorecuero.pdf>. Acesso em 31 de março de 2014.

[11]. CRESCITELLI, Edson; SHIMP, Terence. Comunicação de marketing: integrando propaganda, promoção e outras formas de divulgação. São Paulo: CengageLerning, 2012.

[12]. VIEIRA, Eduardo Infante. Estratégia de marketing na internet. 1. ed. - São Paulo: Prata Editora, p. 29, 2007.

[13]. YIN, Robert K. Estudo de caso: planejamento e métodos; 5. ed. - Porto Alegre: Bookman, p. 51, 2010.

[14]. MONTAÑO, Carlos E. Microempresa na era da globalização: uma abordagem crítica. São Paulo: Cortez, p. 19, 1999.

[15] SEBRAE, 2013

[16]. TIBONI, Conceição Gentil Rebelo. Estatística básica para o curso de turismo. São Paulo: Atlas, p. 50, 2002.

[17]. COSTA, Eliezer Arantes. Gestão estratégica: da empresa que temos para que a empresa que queremos. 2. ed. São Paulo: Saraiva, p.53, 2007.

[18]. CARREIRA, Dorival. Organização, sistemas e métodos: ferramentas para racionalizar as rotinas de trabalho e a estrutura organizacional da empresa. 2. ed. São Paulo: Saraiva, p. 271 , p. $62,2009$.

[19]. SHEEDY, Edna. Guia do empreendedor: para fazer a empresa crescer. São Paulo: Nobel, 1996.

[20]. CHIAVENATO, Idalberto.Administração nos novos tempos. 4. ed. Rio de Janeiro: Campus, 2010.

[21]. TAVARES, Mauro Calixta. Gestão estratégica. 3. ed. São Paulo: Atlas, p. 212, 2010

[22]. TACHIZAWA, Takeshy; REZENDE, Wilson. Gestão empresarial: tendências e desafios - um enfoque na realidade brasileira. São Paulo: Makron Books, p. 118, 2000. 